\title{
FUNCIONAMENTOS DISCURSIVOS DE SATURAÇÃO E OMISSÃO NA NOTÍCIA EM REDE
}

\author{
Solange Mittmann
}

\begin{abstract}
RESUMO: En este texto presento una discusión sobre la reiteración de lo mismo por la necesidad de omitir lo otro. Para eso analizo la sintaxis y las condiciones de producción de una noticia, referida a un accidente de trabajo ocurrido en una fábrica, en la que se ve, de una parte, la necesidad de decir, y de otra, la necesidad de omitir. A través del funcionamiento discursivo de reiteración, se percibe que por la paráfrasis se rellenan los espacios de decir y que, por la repetición de lo mismo, se intenta impedir la diversidad de otras voces y sentidos. Pero el trabajo de contención no puede impedir otras lecturas, puesto que por la misma noticia o a través de otras de distintos periódicos presentes en la internet, el lector puede depararse con otros sentidos posibles en la producción de la noticia.
\end{abstract}

PALAVRAS-CHAVE: formação discursiva, discurso jornalístico, paráfrase, controle de sentidos, sintaxe.

O trabalho do analista do discurso não se esgota na análise de determinado discurso. Trabalhamos sobre o entrecruzamento inextrincável da materialidade linguística com a materialidade histórica, a fim de compreender como se dão os gestos de interpretação. Não nos detemos aos dados linguísticos ou históricos, mas trabalhamos com fatos discursivos, onde se enredam o linguístico e o histórico. E com isso, refletimos sobre o retorno da história no discurso e o retorno do discurso à história, o que nos leva a discutir sobre as forças em confronto nas relações sociais, políticas e econômicas.

É a partir dessa perspectiva que me proponho a discutir, neste texto, o jogo entre a sintaxe textual e as relações econômicas no discurso jornalístico. A partir da análise de uma notícia, pretendo observar, por um lado, como as relações econômicas são discursivizadas diante da identificação dos sujeitos jornalistas com determinada formação discursiva e, por outro, que funcionamentos sintáticos se oferecem para materializar essa discursivização, seja para dizer, seja para silenciar. ${ }^{1}$

O COMPROMETIMENTO COM O MERCADO

Profa. Adjunto da UFRGS e membro do Grupo de Estudos e Pesquisas em Análise do Discurso - GEPAD-RS. Coordenadora do Projeto de Pesquisa Redes de memória: contatos entre discursividades contemporâneas, com apoio PIBIC CNPq/UFRGS.

Uma versão preliminar deste texto foi apresentada, sob o título "A relação fábrica-trabalhador: o enunciado e os nãoditos", no Seminário Nacional de Língua e Literatura, na Universidade de Passo Fundo, em 2008. 
De pronto, como si un remolino hubiera echado raíces en el centro del pueblo llegó la compañía bananera perseguida por la hojarasca. Era una hojarasca revuelta, alborotada, formada por los desperdicios humanos y materiales de los otros pueblos: rastrojos de una guerra civil que cada vez. parecía más remota e inverosímil. La hojarasca era implacable. Todo lo contaminaba de su revuelto olor multitudinario, olor de secreción a flor de piel y de recóndita muerte.

Gabriel García Márquez. La

hojarasca.

A chegada das multinacionais à América Latina sempre esteve acompanhada da hojarasca, causada pelos grandes redemoinhos ambientais e sociais, geralmente com a euforia da grande imprensa. Do mesmo modo que a companhia bananeira na Colômbia, retratada na Macondo de García Márquez, as empresas de celulose vêm dominando grandes áreas no Sul das Américas. E por mais que o Brasil tenha se mantido de costas para os vizinhos - os olhos voltados ora para a Europa, ora para os Estados Unidos -, não se pode negar que sua história tem sido a mesma dos seus pares.

O domínio sobre a terra implica o domínio sobre os homens, como força de trabalho recrutada pelas empresas: os "desperdicios humanos", a mão-de-obra barata e de poucos direitos, graças às "novas" ordens legais das relações de trabalho. Como num eterno retorno ao mesmo, as multinacionais são acolhidas pelas empresas de comunicação, a quem pagam os grandes espaços reservados nos jornais impressos e on line, bem como os horários nobres da televisão e do rádio. Entre uma notícia e outra, emerge "naturalmente" a propaganda de uma das empresas de celulose. Também já não causa estranhamento a propaganda embutida na notícia ufanista: Estado conquista investimentos da Aracruz, Stora Enso, Votorantin, enfim, da empresa da vez.

$\mathrm{Na}$ outra ponta do universo da "informação", é recorrente o discurso de que o cidadão leitor estará melhor preparado para enfrentar o cotidiano quanto mais acesso tiver a assuntos diversos através de textos jornalísticos, sobretudo, notícias - nesses mesmos suportes onde estão entremeadas as propagandas. Não bastasse a restrição do que pode e deve ser dito nos discursos jornalísticos comprometidos com os interesses de mercado, o leitor se vê intimidado pela falta de tempo para dar conta de tudo o que deve ler/saber e, assim, a variedade acaba por ocupar o lugar da reflexão.

Têm-se, então, textos que apresentam pequenos nacos de realidade construída, sustentando a tradição da fórmula telegráfica quem-o que-quando-onde, com cada vez menos espaço para o porquê. E por espaço quero dizer tanto o número de caracteres reservados à notícia - já que a folha do jornal ou a tela do computador têm os espaços previamente delimitados e até preenchidos - como o espaço do dizível a partir da posição assumida pela empresa de jornalismo a respeito do fato noticiado. Afinal, os dois espaços estão interligados.

Além disso, a possibilidade do recorta-e-cola tanto do release da empresa objeto da notícia, como dos textos prêt-à-porter das agências de notícias (Reuters, EFE e AFP dominam esse mercado) resulta em quase nenhum trabalho de (re)escritura e muito menos de investigação por parte de grande parcela de jornalistas, ou seja, há um silenciamento disfarçado de comodidade: pela lei do menor esforço, muitos jornalistas são silenciados pelas empresas midiáticas. Assim, o que o leitor tem diante de si é um discurso amputado, sem o principal, que é a discussão dialética do fato noticiado, capaz de levantar os possíveis porquês. 
Meus trabalhos de pesquisa têm andado nesse sentido, pois venho propondo a exploração pelo ciberespaço desses dizeres que revelam os não-ditos, analisando os processos de contenção e deslizamento de sentidos em temas de interesse social. E tenho olhado com especial atenção para as notícias.

Este texto é resultado de uma dessas caminhadas pelas trilhas oferecidas pela internet a partir de uma pista dessas que saltam aos olhos e que acabam por laçar o leitor pesquisador. Partindo do título de uma notícia publicada no site do jornal Zero Hora, farei aqui um percurso pelos ditos do noticiado, mas, principalmente, por alguns nãoditos. Com isso tentarei mostrar como algumas regularidades sintáticas funcionam na tentativa de controle do que pode e deve ser dito ou lido. Em seguida, mostrarei uma breve seleção de títulos de notícias de outros jornais on line a respeito do mesmo fato noticiado em Zero Hora.

\section{MODOS DE DIZER E DE NÃO DIZER EM UMA NOTÍCIA}

Lendo a versão on line do jornal Zero Hora (em anexo), deparei-me com o título de uma notícia que me instigou a percorrer um caminho de busca de não ditos:

\section{Trabalhadores de fábricas de celulose do rio Uruguai são medicados.}

Pareceu-me que a notícia seria uma continuidade de alguma outra anterior que tivesse abordado algum fato ocorrido com os trabalhadores que os levassem a ser medicados: um acidente de trabalho, uma virose... Afinal, ser medicado é uma consequiência de um fato e não o fato em si. Percorri o site em busca de notícias anteriores, mas não havia nada. Fiquei me perguntando por que o jornalista não apresentou no título o fato em si, mas um resquício. Que sentidos estavam sendo represados, controlados ou mesmo impedidos nesse título? E por quê? Além disso, se era preciso omitir o fato, por que a empresa jornalística noticiava? Afinal, ela poderia simplesmente ignorar o fato, como, aliás, fez nas edições seguintes. Qual era a motivação para esse jogo que envolvia noticiar e silenciar?

Percorrer o texto da notícia foi um trabalho de arqueologia, de catar peças e reorganizá-las. Se a autoria é uma função responsável por organizar as diferentes vozes levando ao efeito de unidade, a análise pode desfazer essa organização e estabelecendo uma outra, levando a um outro efeito. É isso o que farei, agora, com a notícia.

Os trabalhadores do título são retomados no subtítulo com o que parece ter sido a causa de terem sido medicados:

\section{Funcionários relataram estar com irritação nos olhos.}

Veja-se que não está sendo dito, no título, nem no subtítulo, que algo irritou os olhos dos funcionários e que, então, tiveram que ser medicados. Está sendo dito que eles "relataram estar com irritação nos olhos". E o verbo de dizer pode, inclusive, desencadear para o leitor a dúvida sobre se havia mesmo irritação, ou não. O título não apresenta responsabilização das empresas, coloca-as em segundo plano: como adjunto que situa os trabalhadores. A responsabilidade pelo fato noticiado até então é dos funcionários: eles relataram, por isso eles foram medicados.

Se o título e o subtítulo dão essa sensação de falta - o que teria acontecido mesmo? -, o lide (lugar onde geralmente se apresentam os dados centrais que serão desenvolvidos na notícia) traz na própria sintaxe uma seqüência de faltas: 
Quatro trabalhadores de uma empresa contratada pela finlandesa Botnia, no Uruguai, tiveram de ser medicados depois de uma 'irritação leve' nos olhos e nas vias respiratórias.

Com a topicalização dos trabalhadores - da mesma forma que no título e no subtítulo -, esses são apresentados como centro da notícia. Ao mesmo tempo, a empresa da qual são contratados tem, até então, o nome suprimido, aparecendo apenas como "uma empresa contratada pela finlandesa Botnia" - o que no título constava de forma ainda mais nebulosa, inclusive no plural: "fábricas de celulose do rio Uruguai".

Como é comum nos processos de retomadas e qualificações, revela-se aos poucos quem são os sujeitos de que a notícia fala: não são trabalhadores autônomos, são funcionários, e são quatro. E o fato não ocorreu com funcionários da multinacional Botnia, mas com trabalhadores terceirizados - característica das relações trabalhistas atuais, em que grandes empresas terceirizam a mão-de-obra a fim de não responsabilizar-se por ela.

Mas há um outro funcionamento da retomada, mais importante do que esse de acréscimo de informações (dados) sobre o objeto de que se fala, que é o funcionamento (fato) parafrástico: retoma-se o dito e agregam-se outros dizeres para manter o mesmo, para circundar o sentido. Assim, se numa perspectiva textual, trata-se de uma progressão e, portanto, abertura para possibilidades de sentido, na perspectiva discursiva, trata-se de uma contenção, ou seja, trata-se de reter os sentidos diante de possíveis deslizamentos. Isso não significa, é claro, o impedimento de deslizes, já que não estou falando aqui de uma transmissão de informação, mas de efeito de sentidos, de acordo com a definição de Pêcheux (1993, p.82). Trata-se de um jogo de forças entre a contenção e o deslizamento, que é o jogo de forças próprio à produção de discursos.

A apassivação em "ser medicados" e a nominalização em "irritação" possibilitam omitir os agentes, o que é um recurso recorrente na notícia. Aqui não se tem o que provocou a irritação, e os trabalhadores aparecem como únicos envolvidos no incidente. Além disso, "irritação" não aparece explicitamente como causa de "tiveram de ser medicados", pois o conector "depois de", que interliga os dois fatos, organiza-os numa sequência em certa ordem temporal. Essa conexão só pode ser tomada como causalidade a partir do acionamento de uma memória discursiva - ou seja, uma memória "que, face a um texto que surge como acontecimento a ler, vem restabelecer os 'implícitos' (...) de que sua leitura necessita" (Pêcheux, 1999, p.52) - que restabelece que a "irritação" leva à necessidade de "ser medicados", ou que "ser medicados" é um fato consequente que tem como causa a "irritação".

Além da apresentação do que havia sido omitido no subtítulo, isto é, que a irritação não foi apenas nos olhos, como lá constava, mas também nas vias respiratórias, é interessante notar a presença das aspas naquilo que seria a causa do fato noticiado: "uma 'irritação leve' nos olhos e nas vias respiratórias". As aspas podem ser lidas como uma reafirmação de uma voz outra, que é a que fornece as "informações" da notícia, mas também como uma ironia do jornalista, negando que a irritação tenha sido leve. Talvez esse seja o único ponto de escape diante de um posicionamento que é assumido do início ao fim da notícia. Uma discrepância que deixa a marca da contradição constitutiva. Quer dizer, a reafirmação constante de um posicionamento traz em si mesma a contradição - reafirma-se para silenciar a voz oponente -, mas essa voz oponente pode em certo momento irromper no fio do discurso ou na leitura. 
O posicionamento a que me refiro é o de defesa da empresa de celulose. E é esse posicionamento que conduz as reiterações na notícia. Ou seja, trata-se da identificação com uma formação discursiva como espaço de reformulação-paráfrase (conforme a definição de Pêcheux, 1995, p.172). A voz que fala é a voz da empresa, como explicita o sublide:

Os trabalhadores da companhia terceirizada tiveram alta após permanecerem em observação depois do incidente ocorrido na terça-feira, de acordo com fontes da Botnia.

As determinações que circundam a apresentação do fato - "depois do incidente ocorrido na terça-feira" - leva ao efeito de que o incidente já foi, em algum momento, apresentado ao leitor. Mas, como disse anteriormente, não havia, no site, nenhuma notícia anterior sobre esse fato. Assim como estão em suspenso os responsáveis pelo incidente, também o próprio incidente, até aqui, permanece em suspenso.

Os trabalhadores continuam aparecendo como únicos envolvidos: "tiveram alta após permanecerem em observação". E a empresa continua não aparecendo como responsável pelo fato, o que é de se esperar, já que vêm dela as informações. Se a expressão de dizer "de acordo com" revela que a construção da notícia vem da própria empresa de celulose, a empresa de jornalismo se mostra "em acordo com" a perspectiva da empresa. Não há, em todo o texto, manifestação direta de nenhuma outra "fonte" que não sejam "fontes da Botnia". Como não há manifestação de qualquer outra perspectiva, que só pode ser recuperada através do que não é dito.

Embora os trabalhadores sejam o foco, desde o título, em nenhum momento sua voz se manifesta na notícia, a não ser marcando aquela possibilidade quase duvidosa de que falei antes: eles foram medicados não porque sofreram uma irritação, mas porque "relataram estar" com irritação. E para quem relataram? Não parece ter sido para o jornalista, já que os trabalhadores não são nomeados como entrevistados. Ou seja, o discurso dos trabalhadores é intermediado (construído) pelo discurso da empresa.

Um outro funcionamento que contribui para a reiteração da posição assumida de dizer e não dizer a partir da formação discursiva com que o sujeito se identifica - é a apresentação invertida dos fatos, tanto no lide como no sublide, marcada pelos adjuntos "após" e "depois de", o que acaba funcionando como uma opacificação da relação entre causa e conseqüência, já que as conseqüências acabam aparecendo como fatos em si.

A explicação da relação causa-conseqüência é substituída por uma construção que apresenta os fatos em conta-gotas, o que ocorre desde o início do texto: no título, topicaliza-se que os trabalhadores foram medicados (a conseqüência), o que dá realce a uma atitude positiva da empresa em medicar os funcionários, ao mesmo tempo em que se oculta o que levou a (a causa) terem que ser medicados; no subtítulo, apresenta-se não o fato em si (a causa), mas os sintomas relatados pelos funcionários (a conseqüência); no lide, repete-se que os trabalhadores tiveram de ser medicados (consequência); no sublide, novos fatos posteriores (consequências) são apresentados.

Percebe-se, portanto, uma reiteração de um mesmo posicionamento pela apresentação de fatos em uma organização cronológica invertida. A ordem de apresentação dos fatos centra as informações sobre os trabalhadores:

1) são medicados,

2) relataram estar com irritação, 
3) tiveram de ser medicados,

4) depois de uma 'irritação leve',

5) tiveram alta,

6) após permanecerem em observação

e coloca à parte a causa de tais fatos:

7) depois do incidente ocorrido

confundindo e ocultando uma ordem lógica de causa-conseqüência, que poderia ser assim descrita:

$1^{\circ}$.) ocorreu um incidente,

$2^{\circ}$.) que causou irritação nos olhos dos trabalhadores,

$3^{\circ}$.) que, por isso, foram internados, medicados e observados,

$4^{\circ}$.) e só então tiveram alta.

A organização - devidamente desorganizada cronologicamente - dos fatos, com a substituição dos conectores de causa-conseqüência por conectores temporais, faz com que cada fato seja percebido independentemente dos outros. Esse fator também contribui para acentuar ou minimizar cada tema abordado. Mas, mesmo com essa reorganização que fiz da ordem dos fatos, evidenciando tais relações, continua a omissão do que, afinal, aconteceu que desencadeou os fatos relatados até aqui.

$\mathrm{O}$ incidente em si só é revelado no meio da notícia:

Os empregados atingidos trabalham na Andritz, companhia terceirizada pela Botnia, $e$ estiveram nas torres de resfriamento da estação de tratamento de água e sofreram uma leve irritação nos olhos e nas vias respiratórias devido à presença de dióxido de cloro, segundo a gerente de Comunicações da empresa finlandesa, Florencia Herrera.

Veja-se que não está dito que o dióxido de cloro provocou a irritação nos olhos e nas vias respiratórias, mas que os funcionários "sofreram uma leve irritação devido à presença do dióxido de cloro". Também não está dito que os funcionários trabalhavam no local expostos ao dióxido de cloro, mas que eles "estiveram nas torres" onde havia dióxido de cloro - o leitor pode, inclusive, concluir que os funcionários seriam os responsáveis pelo incidente por estarem no local em que não deveriam estar. A conclusão a que o leitor pode chegar é a de que foi a ação dos funcionários e não do dióxido de cloro o que provocou a irritação.

Note-se ainda que a irritação é minimizada com o adjetivo "leve", que aparece por duas vezes na notícia, o que faz crer que foi um fato sem importância e que a internação - desnecessária, portanto - ocorreu apenas por precaução, por excessivo zelo da empresa com a saúde dos trabalhadores. Esse zelo é apresentado a seguir:

- Os operários foram internados por precaução, e ficaram em observação por 12 horas, com exceção de um deles, que ficou um dia inteiro, pois já tinha histórico de problemas respiratórios. Todos receberam alta - completou.

A minimização do incidente, através do aparecimento, por duas vezes, de "irritação leve", leva a um processo de sustentação, isto é, "constitui uma espécie de retorno do saber no pensamento" (Pêcheux, 1995, p.111), para a formulação "por precaução". Assim, "leve" não funciona como mero qualificador, mas evoca um outro saber - se a irritação foi leve, não havia necessidade de internação - oferecendo 
sustentação a "por precaução", que passa a ocupar o lugar da causa. Ou seja, a precaução da empresa é apresentada como motivo da internação dos trabalhadores, e não a irritação provocada, já que esta foi leve e, portanto, não exigia internação. Tanto que, na notícia, o tempo maior de internação de um dos trabalhadores se deveu não a conseqüências mais graves do incidente, mas apenas ao histórico do próprio paciente, o que é reforçado com o operador "já". Novamente, o trabalhador é responsabilizado.

Essa construção leva ao efeito de sentido de que se trata de uma empresa zelosa, responsável pelos cuidados com os funcionários terceirizados, e também de que a responsabilidade pelo ocorrido é dos próprios trabalhadores, já que estiveram onde havia a presença de dióxido de cloro e um deles já apresentava histórico de problemas de saúde. Por isso, os trabalhadores continuam sendo topicalizados, como em todas as formulações anteriores:

- Trabalhadores de fábricas de celulose do rio Uruguai

- Funcionários

- Quatro trabalhadores de uma empresa contratada

- Os trabalhadores da companhia terceirizada

- Os empregados atingidos

- Os operários

Como se pode observar, a correferência e a recorrência de paralelismo, como funcionamentos não apenas lingüísticos/textuais, mas discursivos, conduzem o sentido numa direção, reiterando a posição assumida no discurso. Como afirmei antes, há uma contenção a possíveis deslizamentos de sentido. Quer dizer, essa forma de repetição satura os espaços de dizer, apresentando a interpretação numa única direção, a partir da identificação com uma formação discursiva. Neste caso, a direção é de defesa da empresa e responsabilização dos trabalhadores.

Como já disse, o relato a respeito do incidente é oferecido pela própria empresa. Isso se evidencia pelo fato de que as expressões de dizer sustentam todo o discurso. As informações apresentadas sobre o incidente em si são relatadas pela Gerente de Comunicações da Botnia: "de acordo com fontes da Botnia", "segundo a gerente de Comunicações da empresa finlandesa" e "completou". A evidência de uma cópia do release da empresa, com quase nenhum trabalho (ou talvez nenhum) por parte do jornalista de Zero Hora ou da agência EFE (que assina a notícia), se dá, sobretudo, com as informações que são expostas no parágrafo seguinte:

A Botnia, que começou a operar no Uruguai em novembro, investiu US\$ 1,2 bilhão em uma fábrica de celulose em Fray Bentos (300 quilômetros a noroeste de Montevidéu), na margem leste do rio Uruguai, na fronteira com a Argentina.

A relação entre o incidente que provocou a internação dos trabalhadores, isto é, o fato noticiado em si, e o montante do investimento da empresa na fábrica não pode ser interpretada horizontalmente. Em realidade, há um deslocamento de foco: do fato que precisa ser noticiado para a valorização da imagem da empresa. Tanto que os trabalhadores, que eram até então o tópico de todos os enunciados, a partir desse momento, não são mais citados na notícia. $O$ aspecto social da relação patrãoempregado acaba sendo abafado pelo aspecto econômico do investimento da empresa no país: "investiu US\$1,2 bilhão".

Nesse parágrafo, há uma omissão da voz do jornalista cuja função é noticiar e 
explicar o fato, e impõe-se o discurso pronto da empresa. Cabe aqui, então, substituir a expressão "voz do jornalista", que leva ao imaginário de um sujeito autor, para "voz de jornalista" - daí se poder falar em release -, que aponta para uma outra função própria do discurso jornalístico, que é o seu caráter pedagógico: explicar o fato noticiado e situar o leitor.

Assim, se há omissão da voz do jornalista, há uma voz de jornalista que emerge no papel pedagógico de, por exemplo, situar o leitor sobre a localização da fábrica e, portanto, do incidente, ainda que de maneira um pouco confusa no decorrer da notícia:

- fábricas de celulose do rio Uruguai;

- finlandesa Botnia, no Uruguai;

- Andritz, companhia terceirizada pela Botnia

- em Fray Bentos (300 quilômetros a noroeste de Montevidéu),

- na margem leste do rio Uruguai,

- na fronteira com a Argentina.

A partir desse aspecto da localização, essa mesma voz de jornalista situa também para o leitor o entorno histórico do fato:

Buenos Aires alega que a indústria contamina a água, e protagonizou com Montevidéu um longo conflito.

O Uruguai também enfrenta um processo na Corte Internacional de Justiça de Haia apresentado pela Argentina, após ser acusado de violar o Tratado do Rio Uruguai, firmado entre os dois países.

O gesto pedagógico de situar a empresa no espaço geográfico e no contexto histórico contribui para o efeito de verdade do discurso jornalístico. O deslocamento do foco do incidente para a importância econômica da empresa, no parágrafo anterior, e sua localização possibilita a apresentação do conflito envolvendo a empresa - "a indústria contamina a água" -, mantendo o mesmo posicionamento de defesa desta, tanto que o fato é amenizado com dois funcionamentos, já analisados no início deste texto. O primeiro funcionamento é levar ao efeito dúvida ao não afirmar que a indústria contamina a água, mas fazendo funcionar o verbo de dizer: "Buenos Aires alega" - da mesma forma que havia sido feito com o discurso dos funcionários, que "relataram estar com irritação". O segundo funcionamento é a topicalização dos responsáveis: se há uma topicalização de "A Botnia" no recorte anterior, quando a empresa é exaltada por seu investimento, no momento de apresentar o conflito, o foco é deslocado ora para "Buenos Aires", ora para "O Uruguai". Em nenhum dos casos, há responsabilização direta da empresa.

Afinal, não está dito na notícia que o confronto entre Argentina e Uruguai se deve à defesa, por este último, da instalação de fábricas de celulose (como a Botnia) no lado uruguaio do rio fronteiriço, com a conseqüente poluição para os dois países. Novamente, as informações do texto são apresentadas como independentes.

Ao final do texto, a assinatura da agência de notícias espanhola EFE, que se apresenta como responsável pela notícia. Fato que tem importância para a análise comparativa que apresentarei a seguir.

\section{OUTRAS NOTÍCIAS, OUTROS DITOS?}


Se, por um lado, a notícia aparece como uma construção rápida e fugaz de um pedaço de realidade, constituindo-se materialmente pela falta de contextualização e pela falta de relação entre os fatos apresentados - tudo justificado pela ilusão de completude do esquema informacional -, por outro, o ciberespaço oferece diferentes notícias que a internet não vêm da mesma "fonte", ou que, quando vêm, mostram o trabalho de reescritura do jornalista.

Quando se encontram diferentes posicionamentos sobre um fato, já não se tem simples variedade, como ocorre com a valorização da velocidade com que se apreende o maior número de informações - como descrevi na introdução -, mas diversidade.

Assim, em lugar de um silenciamento imposto por reiterações, o leitor pode encontrar em outros lugares os não ditos de uma notícia, observar os deslizes de sentido e, com isso, o próprio processo de contenção do que não pode e não deve ser dito, lido, interpretado. É claro que, para essa nova postura diante do que as novas tecnologias oferecem - notícias em "tempo real" -, é necessária, além da acessibilidade, a formação de um leitor que perceba a diferença entre variedade e diversidade de discursos.

Aproveitando a facilidade que a internet propicia de acesso a diferentes jornais, fiz uma busca por outras notícias sobre o mesmo fato e com a mesma data de Zero Hora, 15 de dezembro de 2007.

Encontrei uma versão em português bastante semelhante no site de notícias NotiEmail, que apresenta informações do mundo iberoamericano e tem centros de contatos nos Estados Unidos (em Miami, local significativo para o povo iberoamericano) e na Venezuela. Na página Brasil, a notícia recebe o título

Trabalhadores que atuam nas fábricas de celulose do rio Uruguai são medicados. http://brasil.notiemail.com/noticia.asp?nt=11808216\&cty=2

O título marca a mesma posição de Zero Hora, topicalizando os trabalhadores e omitindo tanto o incidente, como os nomes das empresas e, é claro, a responsabilidade destas no incidente. Ao mesmo tempo, apresenta a perspectiva dos patrões de terem prestado assistência aos funcionários. Ao contrário de Zero Hora, não traz subtítulo.

Já na página Uruguay no mesmo NotiEmail, o título difere bastante, apresentando de imediato o nome da multinacional:

Contratados de Botnia afrontan irritación leve de ojos y vías respiratorias.

http://uruguay.notiemail.com/noticia.asp?nt=11808082\&cty=11

Além disso, cita os sintomas de forma mais detalhada que no subtítulo de Zero Hora. É interessante notar como, num mesmo site, sob a assinatura de uma mesma agência - EFE -, o que parece ser a mesma notícia, já é outra, assumindo uma outra posição. Por outro lado, mantém a perspectiva favorável à empresa através do adjetivo "leve", desta vez sem aspas.

Podemos perceber, assim, duas posições-sujeito em uma mesma Formação Discursiva: uma posição-sujeito com a qual estão identificadas as notícias de Zero Hora e do NotiEmail Brasil, e outra posição-sujeito com a qual está identificada a notícia do NotiEmail Uruguay.

Totalmente diverso dos anteriores, é o título da notícia publicada no jornal argentino Página 12, com a assinatura da agência estatal argentina Telám: 
Cuatro trabajadores intoxicados en Botnia

http://www.pagina12.com.ar/imprimir/diario/ultimas/20-96218-2007-12-15.html

O título, ao contrário dos anteriores, não apresenta os sintomas (irritação), mas a sua causa (intoxicação, palavra que não aparece nos textos anteriores). E o antetítulo diz mais:

Es el cuarto incidente que se produce en la planta.

O que está silenciado no trecho de contextualização histórica nos textos anteriores, aqui é dito. Ou seja, enquanto que, na notícia de Zero Hora, o não-dito constitui o dito na medida em que este se esquiva daquele e é construído justamente para que aquele não seja dito, na notícia de Página 12, aquele não dito é topicalizado e reforçado.

No corpo da notícia de Página 12, a mesma posição se manifesta:

Permanecieron internados dos días en un centro asistencial de la zona al constatarse irritación en los ojos y en las vías respiratorias por exposición a uno de los productos utilizados en la producción de pasta de celulosa. (...)

Los cuatro trabajadores realizaban tareas en la torre de enfriamiento de la planta de tratamiento de agua, etapa en la que se trabaja con dióxido de cloro, explicaron fuentes de la empresa.

O sintoma irritação nos olhos e nas vias respiratórias - que, em Zero Hora, os trabalhadores relataram estar - nesta notícia foi constatado. Dessa forma, não se produz o efeito de dúvida, mas o efeito de verdade. Enquanto em Zero Hora o sintoma é tratado com desimportância - qualificado como "leve", tanto que os empregados ficaram em observação por doze horas, apenas por precaução - aqui é abordado com gravidade, já que os empregados permaneceram internados por dois dias.

As causas da irritação, que na notícia de Zero Hora - e também das duas páginas citadas do NotiEmail - são silenciadas ou amenizadas, aqui ganham destaque. A conexão de causa-conseqüência - lá substituída por conexão temporal (depois, após) aqui é explicitada (por exposición). Também a responsabilização que, em Zero Hora, se dava sobre os trabalhadores, já que estiveram no local onde havia dióxido de cloro, em Página 12, é apontada para o empregador, na medida em que os trabalhadores realizavam atividade no local e foram expostos ao produto.

Como é possível perceber, ainda que a empresa continue aparecendo como a única "fonte" das "informações" - "explicaram fuentes de la empresa" - a notícia se constrói a partir da identificação com uma outra Formação Discursiva, que denuncia a própria empresa. É claro que essa identificação não é gratuita: a notícia tem como "fonte" a agência estatal argentina de notícias e defende a posição argentina no conflito com o Uruguai contra a instalação das empresas de celulose às margens do rio Uruguai.

\section{ENCERRANDO A DISCUSSÃO}

A análise da notícia de Zero Hora me levou a produzir uma leitura tanto do funcionamento da variedade, pelas formas de reiteração, como da diversidade, pela relação com o não-dito. Esses dois funcionamentos só podem ser interpretados a partir das condições de produção, isto é, do confronto entre Formações Discursivas e da diferença entre posições-sujeito numa mesma Formação Discursiva dominante. 
O funcionamento de um paralelismo sintático que topicaliza os trabalhadores com substituições lexicais - marca uma reiteração discursiva que é a de responsabilizálos pelo incidente, saturando os sentidos. Esta repetição horizontal satura o dito para que não haja espaço para o não-dito. Da mesma forma, a apresentação dos fatos como se fossem isolados, cada um em seu tempo particular, omite a relação de causa e consequência, o que leva ao efeito de que não é necessário apresentar as causas - os "porquês" tão esquecidos nas notícias ultimamente.

Se na notícia de Zero Hora não há manifestação de outra perspectiva que não seja a da própria empresa - daí a repetição horizontal - essa outra perspectiva está ali presente. O não-dito constitui o dito. É uma presença ausente, conforme descrevem Courtine e Marandin (1981), ao abordarem a repetição vertical, isto é, a memória lacunar. É essa memória lacunar que sustenta a apresentação dos fatos como se fossem independentes e em ordem cronológica invertida.

Se, por um lado, todo discurso é constituído pelo próprio não-dito e, por isso, não tem início nem fim, a oportunidade, facilitada pela internet, de observar outros discursos auxilia o levantamento dos não-ditos num texto que podem ser encontrados como ditos em outros textos, produzidos a partir da identificação com outras Formações Discursivas.

\section{ANEXO}

\section{ZERO HORA Mundo I 15/12/2007 I 20h58min}

\section{Trabalhadores de fábricas de celulose do rio Uruguai são medicados} Funcionários relataram estar com irritação nos olhos

Quatro trabalhadores de uma empresa contratada pela finlandesa Botnia, no Uruguai, tiveram de ser medicados depois de uma "irritação leve" nos olhos e nas vias respiratórias.

Os trabalhadores da companhia terceirizada tiveram alta após permanecerem em observação depois do incidente ocorrido na terça-feira, de acordo com fontes da Botnia.

Os empregados atingidos trabalham na Andritz, companhia terceirizada pela Botnia, e estiveram nas torres de resfriamento da estação de tratamento de água e sofreram uma leve irritação nos olhos e nas vias respiratórias devido à presença de dióxido de cloro, segundo a gerente de Comunicações da empresa finlandesa, Florencia Herrera.

- Os operários foram internados por precaução, e ficaram em observação por 12 horas, com exceção de um deles, que ficou um dia inteiro, pois já tinha histórico de problemas respiratórios. Todos receberam alta - completou.

A Botnia, que começou a operar no Uruguai em novembro, investiu US\$ 1,2 bilhão em uma fábrica de celulose em Fray Bentos (300 quilômetros a noroeste de Montevidéu), na margem leste do rio Uruguai, na fronteira com a Argentina.

Buenos Aires alega que a indústria contamina a água, e protagonizou com Montevidéu um longo conflito.

O Uruguai também enfrenta um processo na Corte Internacional de Justiça de Haia apresentado pela Argentina, após ser acusado de violar o Tratado do Rio Uruguai, firmado entre os dois países. 
EFE

\section{BIBLIOGRAFIA}

COURTINE, Jean-Jacques, MARANDIN, Jean-Marie. Quel objet pour l'analyse du discours? In: CONEIN, Bernard [et al.] Matérialité discoursives. Lille: Presses Universitaires de Lille, 1981. p.21-33.

PÊCHEUX, Michel. Análise automática do discurso. Tradução de Eni P.Orlandi. In: GADET, Françoise; HAK, Tony (orgs.) Por uma análise automática do discurso: uma introdução à obra de Michel Pêcheux. 2.ed. Campinas: Unicamp, 1993. p.61-161.

Papel da memória. In: ACHARD, Pierre [et al.]. Papel da memória. Tradução de José Horta Nunes. Campinas: Pontes, 1999. p.49-57.

. Semântica e discurso: uma crítica à afirmação do óbvio. Tradução de Eni P.Orlandi [et al.] 2.ed. Campinas: Ed. da Unicamp, 1995. 